\title{
An Analytical Optimization Model for Holistic Multiobjective District Energy Management — A Case Study Approach
}

\author{
Mr. Bejay Jayan, Haijiang Li, Yacine Rezgui, Jean-Laurent Hippolyte, and Shaun Howell
}

\begin{abstract}
Efficient management during the operational phase of district energy systems has become increasingly complex due to the various static and dynamic factors involved. Existing deterministic algorithms which are largely based on human experience acquired from specific domains, normally fail to consider the overall efficiency of district energy systems in a holistic way. This paper looks into taking a black box approach by using genetic algorithms (GA) to solve a multiobjectiveoptimization problem conforming to economic, environmental and efficiency standards. This holistic optimization model, takes into account both heat and electricity demand profiles, and was applied in Ebbw Vale district, in Wales. The model helps compute optimized daily schedules for the generation mix in the district and different operational strategies are analyzed using deterministic and genetic algorithm (GA) based combined optimization methods. The results evidence that $\mathrm{GA}$ can be used to define an optimum strategy behind heat production leading to an increase in profit by $32 \%$ and reduction in $\mathrm{CO}_{2}$ emissions by $36 \%$ in the 24 hour period analyzed. This research fits in well with future district energy systems which give priority to integrated and systematic management.
\end{abstract}

Index Terms-Analytical model, district energy management, energy efficiency, genetic algorithms, multiobjective optimization.

\section{INTRODUCTION}

Energy systems in the 21st century are required to meet several important goals towards sustainable development including economic, environmental, and social aspects. A systemic approach needs to be taken to derive feasible integrated solutions to solve complex energy problems [1] as they involve multiple goals, many stakeholders and numerous technologies. Global energy production is increasing at a rate which is more than capable of meeting the rising energy demand [2], however, the rapid growth of $\mathrm{CO}_{2}$ emissions due to increasing energy production, needs to be dealt with. Energy demand reduction or increase in energy efficiency is vital to keep this rate down. Consequently, increased use of renewable energy has gained popularity in countries all around the world. In most cases, these renewable are integrated into the generation mix along with conventional sources of energy. Although there have been

Manuscript received October 20, 2015; revised May 1, 2016. This work was supported in part by EU FP7 Project RESILIENT and also by BRE institute of sustainability of Cardiff University.

The authors are with the School of Engineering, Cardiff University, the Parade, Cardiff, CF24 3AA, UK (e-mail: jayanb@Cardiff.ac.uk, lih@Cardiff.ac.uk, rezguiy@Cardiff.ac.uk, hippolytej@Cardiff.ac.uk, howellsk5@Cardiff.ac.uk). advancements in individual systems, it is also important to be able to increase the overall efficiency, when these systems work together. Learning to manage this pool of resources together, therefore, needs to be given importance.

Decentralized systems at a smaller scale are becoming a feasible choice [1]. They can be used as an alternative or an additional energy supply to the main grid. These include co-generation technologies such as combined heat and power (CHP), using biomass power, solar PV power, wind power...etc. at a local or regional level. Out of these, district heating and cooling systems (DHC) are increasingly being used today [3]. They produce steam and hot/chilled water in a central plant and distribute this to individual buildings (residential and commercial), in its vicinity, through a network of pipelines. They usually tend to be an interesting choice for energy supply in hospitals, industrial parks, office complexes, large campuses (universities), housing estates or small districtswhich can also have a mix of the above buildings. They are known to save energy, consumer space and inhibit air-pollution [4]. DHC systems which use CHP are increasingly being a popular choice not just in Europe, but in many other countries such as United States, China, Russia and India. It is very effective in reducing greenhouse gas emissions (GHG), and increasing economic benefits [5], [6]. DHC networks are also a long-term asset according to the International Energy Agency, as they are a bridge towards the future low carbon energy technologies. For example, they are capable of taking heat from any source including renewable heat sources, hence offering flexibility to integrate new low carbon sources when made available in the future [6]. The development of District Energy Systems - in particular Renewable Energy Sources (RES) - requires new business and technology platforms to manage the increased level of complexity and diversity of global energy management. Intelligent management of these systems is crucial to ensure they are operated at the highest efficiency which takes into account costs, emissions level, and matching demand with supply.

The existing studies for district energy systems optimization largely focus on the planning (design) stage. Very few cases look into the optimization during operational phases, e.g. optimizing operational parameters [7]-[11]. This is due to several factors, including: (1) the integration of renewables and the use of co-generation plants in today's energy mix make the problem more dynamic, uncertain and complex; and (2) many different constraints have to be factored in at each stage of the optimization, and require high computational power to provide near real time results. These are the main challenges that need to be addressed in order to 
achieve the maximum energy efficiency during the complex and dynamic operation stage.

Existing district energy systems can be further improved to achieve better efficiency while using primary energy resources to further reduce their environmental impact [12] . But achieving this can be a complex task and may require certain smart energy management techniques [13].

The research presented here aims to help decision making on thesupply side, provided forecasting of demand is available. The paper looks intoapplyingoptimization methods, through scenarios, to an analytical model, consequently, providing optimum operational strategy for a 24 hour period. The approach is multi objective which considers overall profits and $\mathrm{CO}_{2}$ emissions whilst meeting demand at all times. The schedules help facility manager prioritize which source to use, when, and at what output level, to meet the overall energy demand.

Following this introduction, Section II discusses related work undertaken for operational optimization in district energy systems. Section III introduces the Ebbw Vale pilot case study to which optimization is applied. Section IV describes the multiobjectiveoptimization model and the analytical model which is used as the cost function for the optimization. Section V analyses the results obtained from optimization and some important conclusions on the overall research and plans for future work are detailed in Section VI.

\section{RELATED WORK}

Many of existing work focus on single objective optimization, involving an economic requirement to minimize the overall cost of energy generation [14], [15], [16], [17]. The underpinning research addresses individual systems or technologies in the domain of district energy optimization (for example, boilers, CHP, district heating networks, biomass energy...etc.). Pantaleo et al. [19], [20] aim to optimize operations in smart grid or micro-grid; however, they focus solely on electricity and power domain. These studies lacked a more holistic approach to systematically consider the inter-relationship among different components.

Increasing concern on climate change and $\mathrm{CO}_{2}$ emissions have led to more stringent environmental legislations. Hence, energy managers have also had to try keeping greenhouse gas emissions as low as possible. There is also constant pressure for improvement of the technologies and fuels used; as this help keep emissions from energy production as low as possible. Integration of renewables into the energy generation mix has also become crucial as they help cut down on emissions level. For example, a lot of work has looked into trying to reduce greenhouse gas emissions by integrating biomass plants into the generation mix [18]-[21]. These models were more or less focused on biomass supply chain and distribution; however, they do not look into operational optimization. Biomass is a low carbon option given the low carbon emission released compared to other fossil fuel options. However, the costs of integrating renewables into the generation mix and its management need to be capped, prompting the need for a multiobjective approach.

Arnette A. and Zobel C.W. use mixed-integer linear programming (MILP) techniques to deal with these multi objective problems taking into account renewable energy and conventional sources of energy such as coal plants, but focus on the electricity supply side only [22]. Their approach does not take into account thermal energy. On the other hand, Hire math R.B. et al. introduce a holistic mathematical model which takes into account several objectives, e.g. production and distribution price impact on environment; efficiency of technology used; and also potential labor employment in the area due to decentralized energy planning [23]. This, however, is more related to design optimization than operational optimization. Research has also looked into optimizing the control parameters in the energy systems boiler set points, water flow set-points, and district heating supply [8], [9]. These set-points or schedule of set points remain constant throughout operations phase and do not take into account the day to day changes in demand profiles.

Artificial intelligence (AI) is also being increasingly used for smart control of district energy management systems. Using neural networks, forecasting models, optimization techniques in complex systems to support scheduling, adaptive control, model predictive control, robust pattern detection [1]. A "master slave" optimization technique [24], [25] was used to combine evolutionary algorithms and MILP to solve the district optimization problem. However, the research looks into both sizing of systems along with operating parameters, more relevant for design purposes. Similarly, Maifredi et. al. use a decomposition approach to solve their optimization problem [26]. Here, dynamic programming theory is used to provide dynamic schedules (changes every 24 hours) for electricity and heat production in the co-generation system. The author splits the optimization problem into dynamic problem and static problem with each having their own set of decision variables; but the optimization only considers cost as the objective.

Baños et al. conducted a review of optimization methods applied to renewable and sustainable energy, and showed a significant increase in research papers using optimization methods to solve renewable energy problems, especially for wind and solar systems [27]. The authors review focused on papers that use traditional optimization methods such as mixed-integer and interval linear-programming; quadratic programming and Lagrangian relaxation. They argue that heuristic optimization, such as genetic algorithms and particle swarm optimization, is a growing trend in the field of renewable and sustainable energy management. The review reveals that most of the research has not yet taken a holistic optimization approach as the focus is more on individual renewable energy sources, e.g. wind power, solar energy, hydropower, and bioenergy. Their review also indicates that forecasting techniques are being combined with optimization approaches. For example, Marik et al., combine forecasting along with mixed integer nonlinear programming (MINLP)optimization techniques [9]; whereas, Hashemi developed an offline model to optimize the operations of a combined cooling and heating power (CCHP) system (with storage) and uses non-linear solvers (LINGO 8.0)[11]. However, both studies only consider cost optimization. Ikonen et al., [28] use physical models and multi integer programming to optimize the supply temperature of a district heating network; they propose to extend their work in the future using forecasting models to implement near real time 
optimization. Pini Prato et al., [10] look into thermo-economic optimization of CHP systems using MILP techniques. Even though the optimization focuses on the operational stages, it does not consider emissions as an objective, but rather tries to exploit the heat storage capabilities of the network itself.

The literature reviewed here concludes that very few have looked into multiobjective optimization which is what is needed when considering district energy management at an operational level. Fig. 1 below summarizes the methodology adopted in the work covered in this section and shows that evolutionary algorithms are seldom applied. The authors of this paper believe that taking a black box approach to optimization can be effective and hence adopts this methodology.

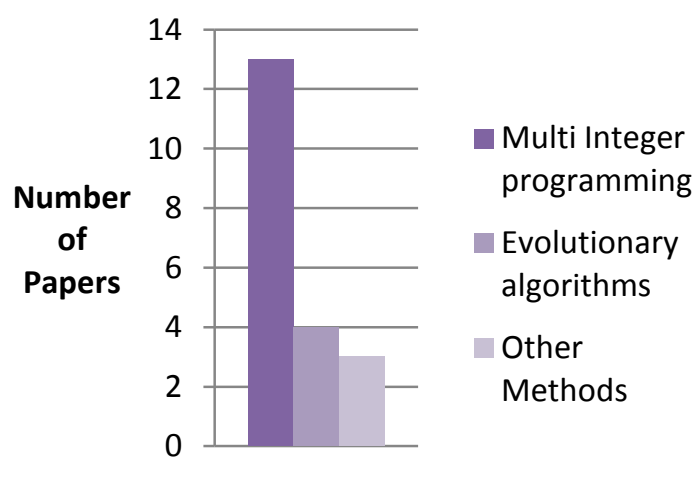

Optimisation Methodology Adopted

Fig. 1. Optimization methodology adopted.

\section{EBBW VALE PILOT INTROdUCtion}

The site is located on the floor of a valley to the south of the town of Ebbw Vale and covers an area of approximately 78 hectares and was formerly occupied by a steelworks, which closed in 1982. Demolition and remediation was subsequently undertaken to create sires for residential, commercial, education and leisure developments. The whole of 'The Works' site is owned by Blaenau Gwent County Borough Council (BGCBC), along with the six buildings/structures forming the Pilot project which are all located at the northern end of the site.

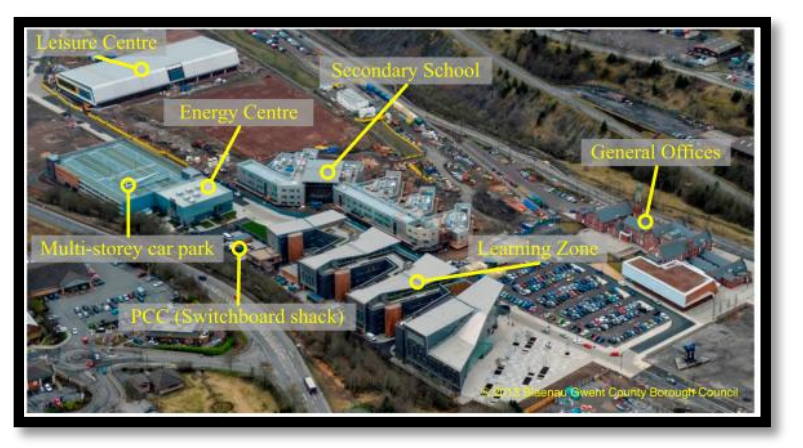

Fig. 2. Ebbw vale site.

The Energy Centre has been designed to provide district heating to commercial developments which will be constructed south of the existing development and also to sites to the north.The six buildings/structures on The Works site which is part of the RESILIENT ${ }^{1}$ Pilot project are: 1) General Offices, 2) Learning Zone (College), 3) Energy Centre, 4) Multistory car park - MSCP, 5) School for 11-16 pupils, 6) Leisure Centre.

An 8MW HV electricity main runs through the site and supplies the School, Leisure Centre and the General Offices. It also supplements the supply from the gas-fired CHP unit to the other buildings. The CHP also works in conjunction with the four gas-fired boilers (any number of boilers can be used based on when they are needed) to provide the district heating system. BGCBC has also installed Biomass boilers in the Energy Centre. The buildings (apart from the General Offices) are new and their design was based on the Energy Centre providing a district heating system with electricity being provided from a combination of the main grid and a CHP unit, and this is the current situation.

\section{A. Thermal Power Supply}

The district heating is provided from 4 gas-fired boilers (ICI REX180 1950kW (input)) and a Cogenco 375kW CHP plant. The boilers are fitted with Nuway MGN2800 burners with 790-2800kW output and each boiler has two Variable Speed Driven (VSD) circulating pumps each rated at $7.5 \mathrm{~kW}$ and run on duty when there is a boiler demand. The CHP plant generally maintains the base loading and the boilers are connected to the external natural gas grid and are all separately metered. The CHP, however, gives priority to meeting heat demand. If the subsequent electricity produced is not enough to meet the demand at any particular time, then electricity is purchased from the national grid. This is a common strategy that can be used [29].

\section{B. Electricity Supply}

The electricity demand for the site is currently being provided through a combination of the CHP plant and the main electrical grid. The CHP provides $375 \mathrm{~kW}$ of electricity to the BGCBC switchboard which is located in the Learning Zone. The supply is used by the Zone, the Energy Centre itself, and the multi-story car park (MSCP). When the load required exceeds this supply capacity the shortfall is obtained directly from the grid supply. If there is a surplus from the CHP this goes to the grid and a payment is received by BGCBC under the FIT (Feed-in Tariff) process. The General Offices, Leisure Centre and the 11-16 School are all connected to the main electricity grid and do not benefit from the CHP or any renewable electricity generation.

Fig. 3 shows the interlinking schematic flow between heat and electricity networks. There is a potential for increasing energy efficiency during operations because the CHP and gas boilers predominantly run at a constant setpoint based on the season. Varying the power within the limits of best practice operations can increase energy efficiency. Also, currently the operation strategy is fixed which is to use CHP to meet the base load, and biomass or gas boilers come online when there is a need for it. Optimization of the strategy, during different demand conditions, can also perhaps bring about economic or environmental savings. Optimizing the energy generation mix at an operational level therefore is a critical issue for the facility managers.

\footnotetext{
${ }^{1}$ Resilient Project, www.resilient-project.eu, (March 10,2015)
} 


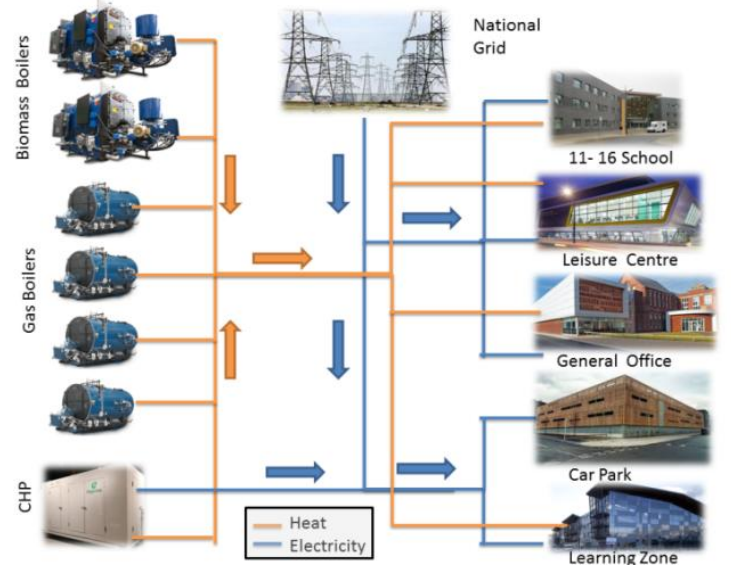

Fig. 3. Heat and electricity schematic flow in the district.

\section{Multiobjective Holistic Optimization}

The study conducted here proposes a multiobjective and holistic optimization model to improve district energy management. The approach here can be termed 'holistic' as the model considers emissions, costs and also energy efficiency as it tries to match demand and supply. Furthermore, it prioritizes heat energy supply but also takes into account electricity production by the cogeneration units. The objectives considered for optimization are $1>$ minimizing operational costs, and $2>$ minimizing carbon emissions. The constraints implemented make sure that the solution also meets the demand at all times during the 24 hour period analyzed. The analysis performed here can help facility managers decide on the operational strategy that needs to be adopted in the district and also find an optimum output power of each source in the district for a 24 hour demand profile.At this stage of the research, there is no real-time prediction of demands for the buildings and the experiments have been carried offline, taking a typical winter demand profile as an example. This was provided from University of Genoa, developers of a load profile generator tool. UNIGE are also partners involved in the RESILIENT project. However, in the future, this work can be integrated with artificial intelligent techniques, such as forecasting models or neural network models, to perform a near real time optimization based on the daily load forecasts of the buildings in the district. Being proactive and forecasting the energy demand takes into account the dynamic changes in demand profiles and this very important to increase the efficiency of the overall system.. Future adaptation of this work would look to use the results of optimization to generate schedules for control parameters such as water supply temperature. One of the limitations is that the study is steady state and hence ignores previous time steps during optimization, and therefore cannot consider latency effect or time constants. This section aims to describe the analytical model along with optimization algorithm in detail including the various objectives, decision variables, and constraints considered.

\section{A. Analytical Model}

The authors preferred to develop the analytical model independently rather than using existing simulation packages such as TRNSYS or Simulink as these packages were considered to be less flexible when it came into the details of the district case study considered here. The analytical model, was able to take into consideration the minute details, for example - renewable heat incentives, carbon taxes, and emissions due to biomass transport. The model uses the heat production schedule, forecasted heat, and electricity demand for a period of 24 hours as the input and calculates the daily operation costs and emissions of carbon dioxide $(\mathrm{kg})$ for the entire district. Fig. 4 below shows the input and output used in the analytical model.

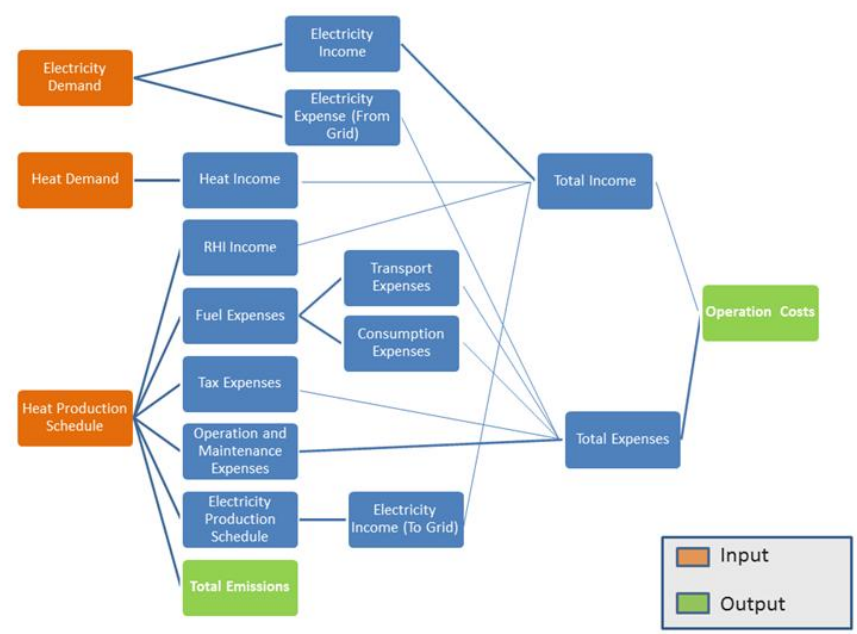

Fig.4. Input and output of the analytical model shown as a workflow.

\begin{tabular}{|c|c|c|c|}
\hline & Symbol & Representation & Value \\
\hline \multirow{5}{*}{ 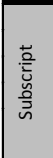 } & 1 & represent the CHP & - \\
\hline & $\mathrm{J}$ & represent a boiler & - \\
\hline & $\mathrm{K}$ & represent a biomass boiler & - \\
\hline & G & represent an energy source system & - \\
\hline & $\mathrm{E}$ & represent the different greenhouse gases & $\begin{array}{l}\mathrm{CO} 2, \mathrm{SO} 2, \mathrm{NOx}, \\
\mathrm{PM}\end{array}$ \\
\hline \multirow{23}{*}{ 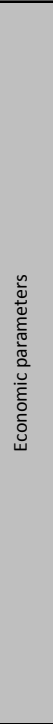 } & \multirow[t]{2}{*}{$P^{E L E C}$} & \multirow[t]{2}{*}{ Purchase price of electricity $\left(£ / k W h_{e l}\right)$} & Day rate: 0.11 \\
\hline & & & Night rate: 0.07 \\
\hline & $P^{G A S}$ & Purchase price of natural gas $\left(£ / k W h_{\text {gas }}\right)$ & 0.0248 \\
\hline & $P^{B I O}$ & Purchase price of biomass $(\mathrm{f} / \mathrm{kg})$ & 0.205 \\
\hline & \multirow[t]{2}{*}{$C_{\text {sale }, c}^{E L E C C}$} & \multirow{2}{*}{$\begin{array}{l}\text { Sale price of electricity (for the energy use system) } \\
\left(£ / k W h_{e l}\right)\end{array}$} & Day rate: 0.11 \\
\hline & & & Night rate: 0.07 \\
\hline & \multirow[t]{3}{*}{$\overline{C_{\text {sale }, n g}^{E L E C}}$} & \multirow{3}{*}{$\begin{array}{l}\text { Sale price of electricity (for the national grid) ( } £ / \\
k W h_{e l} \text { ) }\end{array}$} & Day rate: \\
\hline & & & 0.0764 \\
\hline & & & Night rate:0.03 \\
\hline & $C_{\text {sale }, c}^{H E A T}$ & $\begin{array}{l}\text { Revenue for delivering heat to the energy use system } \\
\left(£ / k W h_{t h}\right)\end{array}$ & 0.0594 \\
\hline & $C_{C H P}^{\text {Maintenance }}$ & Maintenance rate for $\left.\mathrm{CHP}\left(£ / k W h_{e l}\right)\right)$ & 0.0035 \\
\hline & $C^{\text {Maintenance }}$ & Total maintenance cost for Energy Centre & - \\
\hline & $C_{\text {sale }, c}^{\text {RHI }}$ & $\begin{array}{l}\text { Renewable Heat Incentive for biomass production } \\
\left(E / k W h_{t h}\right)\end{array}$ & 0.12 \\
\hline & $Q^{g}$ & Thermal generation of energy source system $\mathrm{g}$ & - \\
\hline & $E^{C H P}$ & Electrical KWh generated by $\mathrm{CHP}(\mathrm{kWh})$ & - \\
\hline & $\eta^{g}$ & $\begin{array}{l}\text { Efficiency of the energy source system } g \\
\text { (dimensionless) }\end{array}$ & - \\
\hline & ${ }^{*} E_{\text {demand }}$ & Electrical energy demand (kWh) & - \\
\hline & $E_{\text {sold }, c}$ & Sold electricity to the energy use system $\left(k W h_{e l}\right)$ & - \\
\hline & $E_{\text {sold }, n g}$ & Sold electricity to the national grid $\left(k W h_{e l}\right)$ & - \\
\hline & $E_{\text {bought }}$ & Electricity bought from the national grid $\left(k W_{e l}\right)$ & - \\
\hline & $Q_{\text {sold }, c}$ & Thermal energy sold to Energy using system & - \\
\hline & $Q_{\text {demand }}$ & Thermal demand (kWh) & \\
\hline & $\mathrm{T}$ & CHP's heat and power ratio (dimensionless) & 0.65 \\
\hline \multirow{5}{*}{ 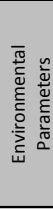 } & $\mu_{e}^{l}$ & $\begin{array}{l}\text { Amount of ' 'e' emitted from the energy source system } \\
\text { using fuel ' } \mathrm{l} \text { ' (kg) }\end{array}$ & - \\
\hline & $\varepsilon_{e}^{l}$ & $\begin{array}{l}\text { Specific emission of e per kWh for energy source } \\
\text { system using fuel I" }(\mathrm{kg} / \mathrm{kWh}))\end{array}$ & Refer to table I \\
\hline & $x^{l}$ & Calorific value of fuel I (kWh/kg) & - \\
\hline & $\mu_{e}^{\text {transport }}$ & Emissions due to transport for biomass (kg) & - \\
\hline & $B \mathrm{Tr}_{\mathrm{c}}$ & $\begin{array}{l}\text { Carbon emission factor for biomass transport. (kgCO2 } \\
/ \text { KgBiomass }-\mathrm{Km})\end{array}$ & 0.00012 \\
\hline \multirow{7}{*}{ 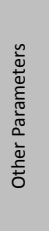 } & $D I S_{P \& E V}$ & $\begin{array}{l}\text { Distance between biomass producer and Ebbw Vale } \\
(\mathrm{km})\end{array}$ & 277 \\
\hline & Cons $^{G A S}$ & Natural gas consumption $\left(k W h_{\text {gas }}\right)$ & - \\
\hline & $N_{G}$ & Number of energy source systems & 7 \\
\hline & $N_{l}$ & Number of types of fuel used & $\begin{array}{l}\text { Biomass, } \\
\text { Natural gas }\end{array}$ \\
\hline & $N_{C H P}$ & Number of CHP & 1 \\
\hline & $N_{B O I L E R}$ & Number of boilers & 4 \\
\hline & $N_{\text {BIOMASS }}$ & Number of biomass boilers & 2 \\
\hline
\end{tabular}


Table I below shows the nomenclature used in Ebbw Vale analytical model.

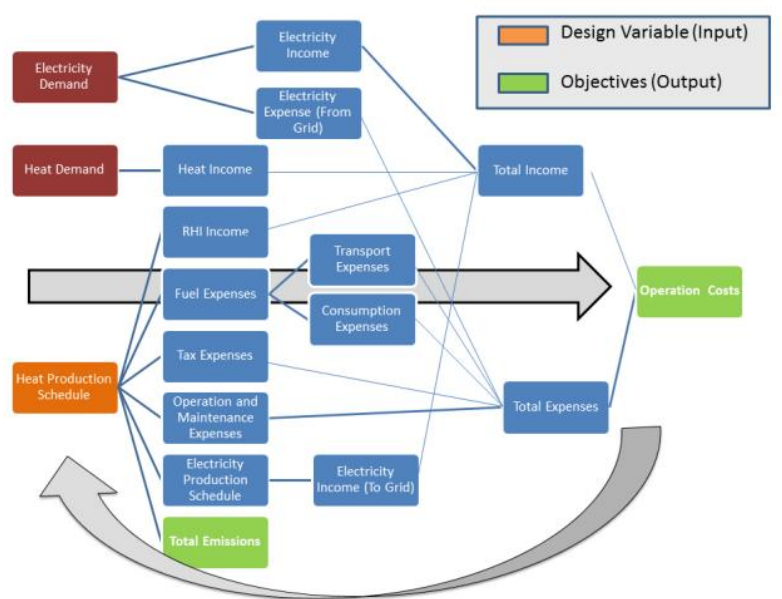

Fig. 5. Optimization model using Ebbw vale mathematical model as a cost function.

District operation simulation equations

The following sets of equations are needed to inform a district operation simulation model. It is used to calculate relevant outputs, e.g. energy production. This section presents the different types of operating equations.

The equations below are used to calculate the production of energy - thermal energy produced from CHP, boiler and biomass boiler; and, the electrical energy produced from the CHP. The thermal energy produced contributes to both cost and emission calculations.

$$
\begin{aligned}
Q^{\text {BOILER }} & =\sum_{j=1}^{N_{\text {BOILER }}} Q_{j} \\
Q^{C H P} & =\sum_{i=1}^{N_{C H P}} Q_{i} \\
Q^{\text {BIOMASS }} & =\sum_{k=1}^{N_{\text {BIOMASS }}} Q_{k}
\end{aligned}
$$

The electrical energy can be calculated as shown below:

$$
E^{C H P}=\sum_{i=1}^{N_{C H P}} E_{i}
$$

$E_{i}$ is calculated using the CHP power to heat ratio given by the CHP manufacturer, as below:

$$
E_{i}=Q_{i} * \tau
$$

Here, $\tau=0.65$, which is obtained from the manufacturer's documents.

The electricity exchanged with the national grid will also contribute towards the cost objective function and is calculated as shown below:

Electricity sold to the national grid:

$$
E_{\text {sold,ng }}=E^{C H P}-E_{\text {demand }}
$$

Electricity bought from the national grid:

$$
E_{\text {bought }}=E_{\text {demand }}-E^{C H P}
$$

The natural gas consumption is used for calculating the cost objective function and is calculated as shown below:

$$
\text { Cons }^{\text {GAS }}=\sum_{g=1}^{N_{G}-N_{\text {BIOMASS }}} \frac{E^{g}+Q^{g}}{\eta^{g}}
$$

\section{B. Optimization Algorithm}

Fig. 5 shows the optimization model applied in the case of Ebbw Vale with inputs and outputs variables.

Objective Functions

The first objective function is related to the operational costs of the district i.e. fuel consumption for energy production and also electricity bought from grid. The aim of this objective function is -

$$
\text { Minimise }\left(C_{\text {energycentre }}-\mathrm{B}_{\text {energycentre }}\right)
$$

$C_{\text {energy center }}$ is the total cost for the energy centre;

$B_{\text {energy centre }}$ is the total income received by the energy centre;

The various costs are calculated as shown below:

$$
\begin{gathered}
C_{\text {energy centre }}=C^{\text {BIOMASS }}+C^{\text {CONS }}+C^{\text {TAXES }}+ \\
C^{\text {Electricity }}+C^{\text {Maintenance }}
\end{gathered}
$$

Here, $C^{\text {TAXES }}$ are the costs due to taxes, $C^{\text {CONS }}$ are the costs due to gas consumption and $C^{\text {BIOMASS }}$ are the costs due to biomass consumption

$$
C^{B I O M A S S}=P^{B I O} \times q_{\text {trans }}
$$

The transport cost for biomass is included in the buying price and hence the transportation costs do not appear in this equation. The storage losses for biomass are ignored because of highly efficient storage system being used in Ebbw Vale along with the best pellet fuel.

$$
\begin{aligned}
& C^{\text {TAXES }}=C_{\text {taxes }} \times\left(N_{C H P} \times \mu_{C O 2}^{C H P}+N_{\text {BIOMASS }} \times \mu_{C O 2}^{\text {BIOMASS }}+\right. \\
& \text { NBOILER } \times \text { CO2BOILER } \\
& \text { (11) } \\
& C^{\text {CONS }}=P^{G A S} \times \text { Cons }^{G A S} \\
& \mathrm{C}^{\text {Electricity }}=E_{\text {bought }} \times P^{E L E C}
\end{aligned}
$$

$C^{\text {Maintenance }}$ includes the maintenance cost of CHP only as they include a regular service, moreover, this rate unlike for other sources can be calculated based on use of CHP for electrical energy produced [30]. Investment costs are not part of the model as the scope of this paper only looks into operational stages of district, therefore, avoiding the static costs which do not affect the operations.

$$
C^{\text {Maintenance }}=C_{C H P}^{\text {Maintenance }} \times E^{\text {CHP }}
$$

Revenue for Energy centre comes from:

1) Electricity sold to Learning Zone,

2) During night times, the excess electricity produced by CHP is sold back to the grid; and finally,

3) Heat energy sold to Learning zone in the district, and

4) Renewable Heat Incentive (RHI) from Biomass production [31]. 


$$
\begin{aligned}
& B_{\text {energy centre }}=C_{\text {sale,c }}^{E L E C} \times E_{\text {sold }, c}+C_{\text {sale }, n g}^{E L E C} \times E_{\text {sold }, n g}+ \\
& C_{\text {sale }, c}^{H E A T} \times \quad Q_{\text {sold }, c}+ \\
& C_{\text {sale }, \mathrm{C}}^{R H I} \times Q^{\text {BIOMASS }}
\end{aligned}
$$

The second objective function is related to greenhouse gas emissions

$$
\text { Minimise } G H G_{\text {emission }}
$$

The aim of this objective is to minimise the total greenhouse gases emissions. This needs to take into account the $\mathrm{CO}_{2}$ equivalent produced from the different fuels used by sources. The greenhouse gas conversion factor for unit energy can be adopted from the Department of Environment, Food \& Rural Affairs (DEFRA) [32] as shown below in Table II.

TABLE II: CARBON DIOXIDE EQUIVALENT

\begin{tabular}{c|c|c}
\hline \hline Fuel Source & Symbol & $\begin{array}{c}\text { Specific Emissions } \\
(\mathrm{Kg} / \mathrm{Kwh})\end{array}$ \\
\hline Natural Gas & $\varepsilon_{\text {KgCO2e }}^{\text {Natural Gas }}$ & 0.1850 \\
\hline Wood Pellets & $\varepsilon_{\text {KgCO2 }}^{\text {Woollet }}$ & 0.0118 \\
\hline \hline
\end{tabular}

Greenhouse gas emissions for electricity bought from the grid is ignored as they are part of life cycle emissions.

When the source ' $\mathrm{g}$ ' is CHP or boilers:

$$
\mu_{K g C O 2 e}^{\text {Natural Gas }}=\varepsilon_{K g C O 2 e}^{\text {Natural Gas }} \times Q^{g}
$$

On the other hand when the energy source ' $\mathrm{g}$ ' is biomass boilers:

$$
\mu_{\text {KgCO2e }}^{\text {Biomass }}=\varepsilon_{\text {KgCO2e }}^{\text {Biomass }} \times\left(Q^{\text {Biomass }}\right)
$$

Emissions due to transport of biomass $\mu_{e}^{\text {transport }}$ also needs to be calculated.

$$
\begin{gathered}
\mu_{K g C O 2}^{\text {transport }}=B T r_{C} * q_{\text {trans }} \times D I S_{P \& E V} \\
q_{\text {trans }}=\frac{Q^{\text {Biomass }}}{\chi^{B I O} \times \eta^{B I O}}
\end{gathered}
$$

Here, $D I S_{P \& E V}=276 \mathrm{~km}$. According to the owners of the district energy system, the nearest biomass producer is PBE Fuels and they are $138 \mathrm{~km}$ away from the site.

The carbon emission factor, $B T r_{c}$, for biomass transport is taken from the biomass energy centre website [33] and is $0.00012 \mathrm{kgCO}_{2} / \mathrm{Kg}$ Biomass $-\mathrm{Km}$. This gives an approximate value for the amount of $\mathrm{CO}_{2}$ produced if biomass is transported by road. By knowing all the emissions, the total greenhouse gas emissions can be calculated as shown below:

$$
G H G_{\text {emission }}=\left(\sum_{l=1}^{N_{l}} \mu_{K g C O 2 e}^{l}\right)+\mu_{K g C O 2}^{\text {transport }}
$$

Decision Variables

According to the IEEE/IEC 61970-301 CIM (Common Information Model) standard, a regular schedule for automation systems can be defined by:

- $\Delta \mathrm{t}$ a time step (a constant value in seconds);

- $t_{s}$ a start date;
- $\quad t_{e}$ an end date;

- $\quad$ an ordered list of $m$ time points.

The CIM contains formalised descriptions of electrical power system components. Out of which the IEC 61970 standard defines the Application Program Interface (API) for Energy Management Systems (EMS). The standard can be used in a wide range of applications. It can be considered to be a tool which integrates any domain in a common power system model facilitating interoperability between applications. Smart grid resources can also be represented as objects, classes and attributes along with their relationships through the standard [34].

In the proposed analytical model, each thermal energy production schedule is represented by a row vector. Let $N_{G}$ be the total number of energy source systems and energy using systems in the district. $\forall g \in\left\{1, \ldots, N_{G}\right\}, Q^{g} \in \mathbb{R}^{m}$, where $\mathrm{m}$ is the number of time points $m=\left|\frac{t_{e}-t_{s}}{\Delta \mathrm{t}}\right|$. Let $g \in\left\{1, \ldots, N_{G}\right\}$, the schedule of energy source system $g$ will be denoted by: $v^{g}=\left\{v_{t}^{g}: t \in \mathrm{T}\right\}$, where $\mathrm{T}$ is the set of time points $(|T|=m)$. For example, $Q^{C H P}$ denotes the production schedule of the CHP generation system of the considered district.

Constraints of the Optimization Algorithm

The first constraint is that the thermal energy being fed into the ring has to exceed the sum of the thermal demand. Here a factor for losses - a safety factor needs to be taken into account - is taken from historical data as mentioned previously. These constraints make sure that demand is met at all times.

$$
Q_{\text {ring }}^{\text {in }} \geq \sum_{b=1}^{N_{b}} Q_{\text {demand }}^{b}
$$

Secondly, CHP, gas boilers and biomass boilers have their own maximum and minimum power capacities. These were implemented in the model as lower bounds and upper bounds of the design variable itself. The lower and upper bounds are presented below in tableIII. Although the biomass boilers have a lower bound which is not equal to zero, the optimization solution can be corrected to make sure biomass boilers are turned off if the demand is already met.

TABLE III: CONSTRAINTS OF ENERGY SOURCES

\begin{tabular}{c|c|c}
\hline \hline & Lower Bound $(\mathrm{Kw})$ & Upper Bound $(\mathrm{Kw})$ \\
\hline CHP & 375 & 401 \\
\hline Biomass Boilers & 124 & 495 \\
\hline Gas Boilers & 0 & 1600 \\
\hline \hline
\end{tabular}

The losses here were taken to be about $20 \%$. This was computed based on the limited amount of historical data that was collected from heat meters in the network.

Optimization Algorithm Implementation

Genetic Algorithms are nature-inspired stochastic optimization algorithms that have the following characteristics:

- Encoding: the decision variables of the problem are encoded into abstract constructs;

- Set-based: the algorithm manipulates a set of abstract constructs (called solutions) simultaneously; 
- Iterative: the solution set is updated dynamically along the run of the algorithm, by applying so-called genetic operators to its elements, the crossover operator that creates new solutions by combining two or more existing solutions and the mutation operator that slightly modifies an existing solution;

- Selection and replacement: a GA aims improve its solution set by iteratively exploring its neighbourhood in the problem's search space (defined by the genetic operators) and by incorporating discovered better solutions;

- Random-based: a GA applies most of the sub-processes mentioned above in a probabilistic manner;

- Black-box: a GA only requires the value of a comparative performance measure for each solution (called evaluation), regardless of how this measure is computed.

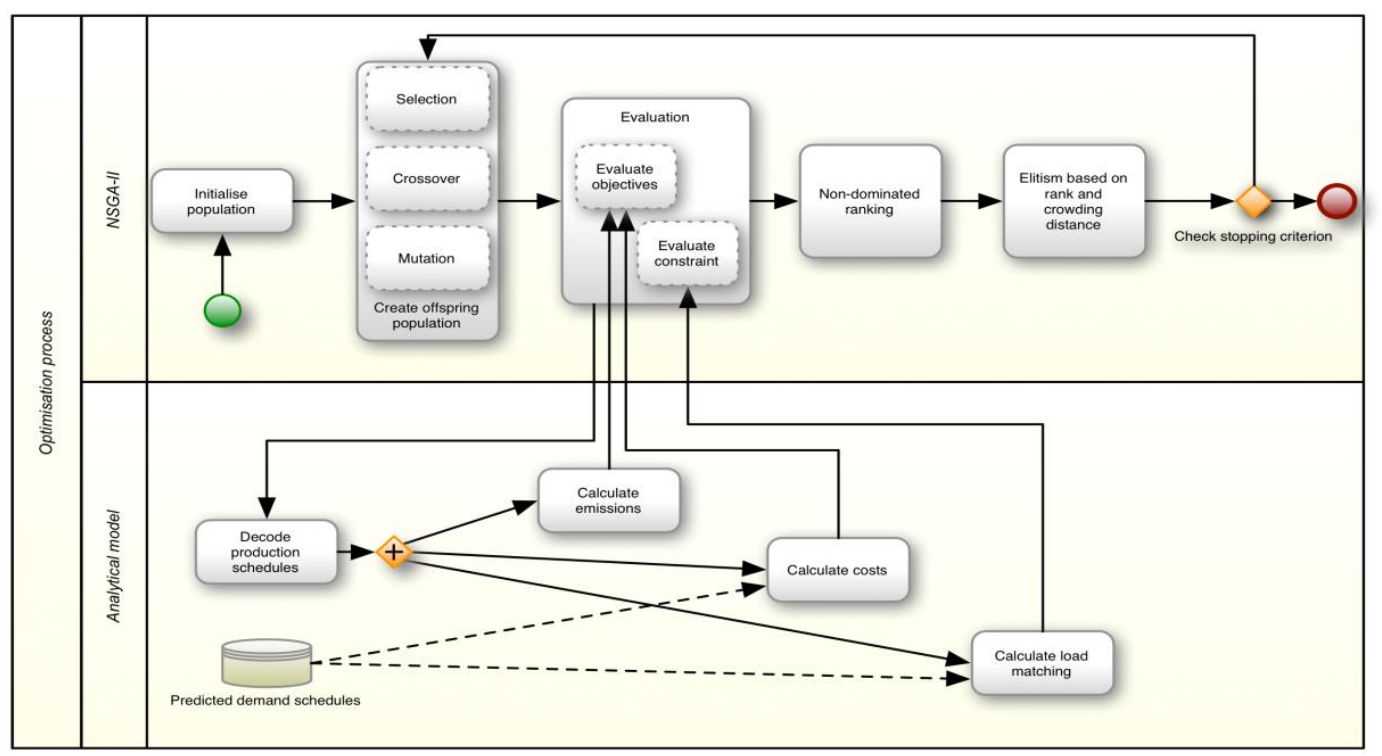

Fig 6. Optimization process workflow.

Here NSGA-II algorithm, developed by Deb et al. [35] , was used and implemented in Matlab ${ }^{2}$. Fig. 6 above shows the overall optimisation process workflow and how the analytical model interacts with the NSGA-II optimisation algorithm. This analytical model is applied to the case of Ebbw Vale district and is used as the cost function for multi objective optimization. The link between optimisation model and analytical model is described in the points below:

- The decision variables, here, are the twenty four hour production schedules in the analytical model for each source $g, Q^{g}$.

- Objective function 1 of the optimisation is linked to the total operational costs, which is as represented earlierin section IV B as ( $\left.C_{\text {energycentre }}-\mathrm{B}_{\text {energycentre }}\right)$

- Objective function 2 of the optimisation is linked to the total operational emissions, which is represented by equation (20) in the analytical model.

- The difference between the heat production schedule, $Q^{g}$ and the heat demand schedule, $Q_{\text {demand }}^{b}$ is computed from the analytical model. Thisis used to evaluate the constraints of the optimisation problems as shown in equation (21).

The crossover operator is a straightforward generalisation of the classical single-point crossover operator, i.e. row vectors of the schedule matrix are crossed from either side of a randomly picked time point. The scope of this paper being a proof-of-concept of an optimisation model, the mutation operator is also basic: when mutation probabilistically occurs, a random value of thermal energy production is given at a

\footnotetext{
${ }^{2}$ http://www.mathworks.com/...nsga-ii--a-multi-objective-optimization-a lgorithm (10 August 2015)
}

randomly picked time point of a randomly picked schedule (respecting the lower and upper bound capacities of the targeted generation system).In order to keep the coherence of the generation schedules, a sub-procedure is applied. This procedure simply balances the thermal productions among generation systems of the same type without affecting the evaluation of the schedule in terms of cost, emissions and energy efficiency. The NSGA-II algorithm used maximum generation as the stopping criterion. In this case it was about 100 generations.

Following the definition of time schedules as decision variables previously, solutions are encoded as $m$-by- $N_{G}$ matrices. Conceptually, they are matrices of regular schedules as standardised in IEEE 61970-301.

\section{RESUlts ANALYSIS}

Two different optimization test cases were conducted to Ebbw Vale pilot and the consequent optimized values were used to compare to the base case (which is the business as usual case). This section presents the testing results and its analysis.

Business as usual case-This is the current operational strategy in Ebbw Vale Pilot wherein it uses CHP, biomass and gas boilers. The CHP is given priority to meet the loads. The smart (deterministic) algorithm tested in this scenario uses CHP to meet the base load; the biomass and gas boilers will come online when required. In this case, biomass boilers are preferred over gas boilers for three reasons: (1) They produce almost 10 times less carbon emissions compared to gas boilers, (2) They have a lower minimum setpoint which 
can reduce the excess energy being produced, and (3) High renewable heat incentive provided for energy produced using biomass boilers making it economically attractive. The share of load produced by each source to meet the demand is shown below in Fig. 7. This scenario uses a deterministic algorithm, which takes a rule-based approach to produce the production profiles. These rules are based on human knowledge. Fig.7 shows demand being perfectly met by production profiles with the available resources. The cost and emission values achieved in this case are shown in Table IV.

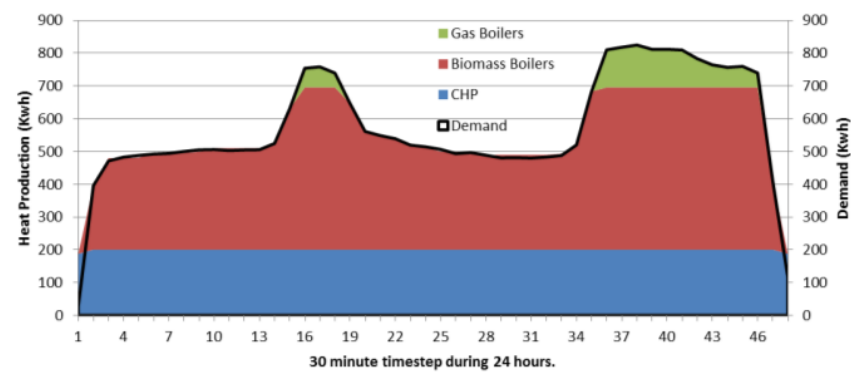

Fig. 7. Energy demand vs. Supply for business as usual scenario.

Scenario 1: Optimization usingNSGA-II- Here the NSGA-II algorithm was used to solve the problem, as its robustness to solve various optimization problems has been widely assessed in the literature. Like other GAs, NSGA-II has user-defined parameters that impact the performance of the algorithm. In order to induce sufficient variety among the population sets visited during an algorithm run, the algorithm choses crossover is 0.9 and population size is 1000 considering the scale of the solutions (3-by-48 matrices). Mutation value was set to 0.05 to make sure that the solution would not converge early.

Fig. 8 shows an example of non-dominated solution provided by NSGA-II. The algorithm was adapted to energy management problem and therefore it makes sure that the demand was met for each time step. The optimization produced many sets of solutions. The cost and emissions value achieved through this scenario is shown in Table IV.

Scenario 2: Optimization using NSGA-II but with a changed strategy - Previous scenario was only able to bring a small amount of savings in terms of emissions, but not much savings in terms of profits. The optimization found very few solutions that were able to meet all constraints and still keep emissions and costs low. In Scenario 2 therefore, the algorithm was flexible to choose another strategy i.e. change the priority order of sources. This brought a drastic improvement in results for the 24 hour demand profile analyzed. Fig. 9 shows how Biomass boilers and Gas Boilers were used instead of CHP. The cost and emissions are shown below in Table IV.

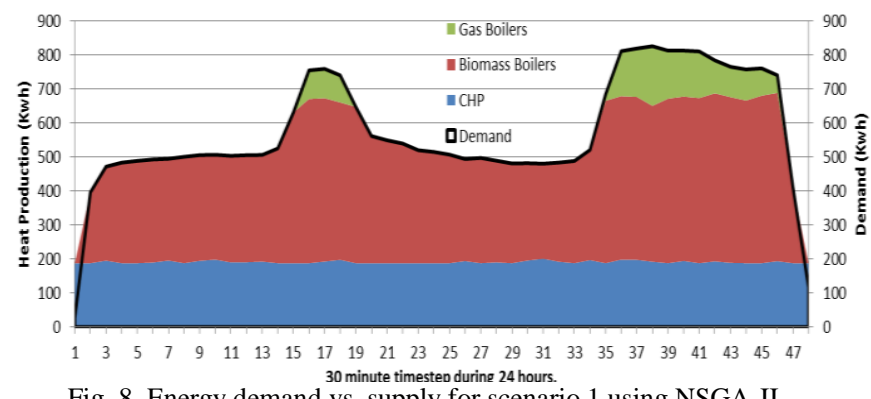

Fig. 8. Energy demand vs. supply for scenario 1 using NSGA-II.

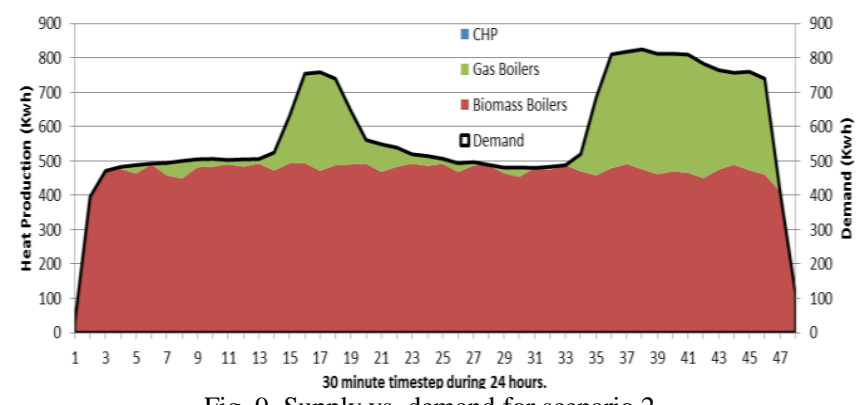

Fig. 9. Supply vs. demand for scenario 2.

All the demand curves presented above include the losses which are approximated at $20 \%$. This approximation is taken from historical data analysis. The objective values calculated along with their computational time for all the cases during a typical winter day is shown below in table IV:

TABLE IV: FINAL RESULTS

\begin{tabular}{l|c|c|c}
\hline \hline & $\begin{array}{c}\text { Business } \\
\text { as usual }\end{array}$ & Scenario 1 & Scenario 2 \\
\hline $\begin{array}{l}\text { Computational time } \\
\text { (seconds) }\end{array}$ & 1.06 & 2372 & 2370 \\
\hline Profit (£) & $£ 1854$ & $£ 1805.18$ & $£ 2442.68$ \\
\hline $\begin{array}{l}\text { Carbon Dioxide emissions } \\
(\text { Kg) }\end{array}$ & 2394.7 & 2374.9 & 1531.9 \\
\hline $\begin{array}{l}\text { No. of Time steps where } \\
\text { demand was not met }\end{array}$ & 0 & 0 & 0 \\
\hline \hline
\end{tabular}

\section{DISCUSSION}

Scenario one applies optimization to 24 hour schedule, however brings very little improvement in results. The emissions were reduced by $0.8 \%$ during the 24 hour period. Profits on the other hand decreased by $2.6 \%$. The NSGA-II failed to improve results which were obtained from using deterministic algorithms in the business as usual scenario. Scenario two on the other hand was made flexible to experiment a different strategy in terms of the priority of sources to be used. This drastically improved the results and increased the profits by $31.8 \%$ and decreased emissions by $36 \%$ when compared to the business as usual case. For the load profile analysed, CHP being turned off and using maximum biomass boilers is a better strategy. The black box approach to optimization clearly gives priority here to the biomass boilers over the CHP. One of the reasons for this could be the high heat incentive received for every unit of energy produced from the biomass boilers. Results might vary with varying demand profiles.Also, the relationship between cost and emissions is non-linear and complex. This is where a black box approach to optimization can be advantageous.

The results show that using GA basedoptimization approach, NSGA-II in this paper, can bring savings in costs and emissions only if it is allowed to be flexible with not only power output but also the strategy. The advantage of using such an optimization solution is that it considers all the constraints and factors, and produces a solution, which is feasible and satisfies all the objectives. In the case of Ebbw vale, the numbers of feasible strategies for running the district are few. However this methodology can be more beneficial in complicated districts.

One challenge would be the computational time for an 
optimized solution to be found. The optimization process currently is time consuming as it takes about 2373 seconds hours on a normal computer with which has the following specification- Intel(R) Core (TM) i7-3930M CPU @ 3.20GHZ Processor Speed, RAM 32 GB. It still can assist facility managers in decision making, provided it is taken as a tool to perform 'day ahead' scheduling. Another alternative would be to consider parallelisation of the optimization process or using high performance computing that deals with the computational time as used previously by authors in [36]. However, the inherent convergence speed of the GA (i.e. the number of production schedule evaluations required to "jump" towards more better non-dominated solutions regardless of computation time) is another alternative the authors intend to investigate. A plethora of GA operator instances (selection, crossover, mutation) from the literature as well as other metaheuristics can be experimented, starting with the ones that are known to solve similar real-world optimization problems and moving towards ones that are tailored for district energy production scheduling. The resulting best-practice metaheuristics set-up for district energy schedule optimization, combined with accurate load prediction and possibly deployed on delocalised high performance computing infrastructures, could be at the heart of a multicriterion [36].

The results achieved in this paper however, already show that GA is able to produce optimized solutions that overcome the most obvious operational strategy devised through human knowledge (heuristics). In this case, for the demand profile suggested, the solution provided suggests turning off the CHP and using more of the biomass boilers and gas boilers. This therefore, can help improve the business as usual case by reducing emissions and increasing the operational profit of the district over the 24 hour period analysed.

\section{CONCLUSION}

The study conducted here looks into taking a multi objective optimization approach with genetic algorithms for district energy management, by aiding facility mangers to device optimum production schedules. The optimization model takes a holistic approach which includes both heat and electricity domains, whilst taking into account all the operational constraints. The results of the study prove that running GA based optimization by just varying the power outputs on a pre-determined strategy does not improve results. However, optimization performed well when the algorithm was flexible with both the output power and the production strategy itself (i.e. order in which sources are used) as well. The optimization applied to the analytical model of Ebbw Vale district shows increase in profits and reduction in emissions when compared to using normal deterministic algorithms.

The only pre-requisite for the optimization problem is the 24 hour demand profile prediction of the various energy consumers in the district. If this is available, such a solution can be deployed in real world by running it as a day ahead scheduling tool. The Demand profiles change every day and hence being pro-active and planning ahead can increase energy efficiency of the overall system.

Future work should look to translate the energy production schedules to the actual setpoint -for example, supply temperature, return temperature, mass flow of water...etc. The current analytical model used is specific to Ebbw Vale case study, but it can also in the future look to integrate renewables and storage facilities. This would make the district energy analytical model generic which can then be easily applied to other district sites with slight alterations. Other GA based optimization algorithms can also be evaluated with this model to check for any improvement in results.

The authors believe that the work produced here fits into the fourth generation of district energy systems which would require a holistic coordination of operations, and would have to also consider the real time variations in demands to improve the overall efficiency. The optimization model presented in this paper would form one module or part of the real time energy management framework would be needed in the future. It would also need other modules such as demand predictions, for example because real-time dynamic changes in district energy demand is seldom taken into account by today's energy management frameworks. Together they would deal with the complex issue of trying to match demand and supply in real time taking into account all the static constraints and objectives.

\section{ACKNOWLEDGMENT}

The authors thank University of Genoa for their support and also special thanks to Prof. Jeff Perren for his support in liaising with pilot site. The authors would also like to acknowledge all the information and help provided by the Blaenau Gwent council.

\section{REFERENCES}

[1] A. A. Bazmi and G. Zahedi, "Sustainable energy systems: Role of optimization modeling techniques in power generation and supply: A review," Renew. Sustain. Energy Rev., vol. 15, no. 8, pp. $3480-3500$, 2011.

[2] Sustainability Review 2012, British Petroleum, 2013.

[3] 2013 Euroheat and Power Annual Highlights, Euroheat \& Power, 2014.

[4] M. Sakawa, K. Kato, S. Ushiro, and M. Inaoka, "Operation planning of district heating and cooling plants using genetic algorithms for mixed integer programming," Appl. Soft Comput., vol. 1, no. 2, pp. 139-150, Aug. 2001.

[5] "Combined heat and power," International Energy Agency, Paris, 2008.

[6] International Energy Agency, Cogeneration and district energy, Paris 2009.

[7] J. Jamot and F. Olsson, "Optimisation of the supply temperature on the southern district heating network in Lund," 2013.

[8] X. Jiang, Z. Jing, Y. Li, Q. Wu, and W. Tang, "Modelling and operation optimization of an integrated energy based direct district water-heating system," Energy, vol. 64, pp. 375-388, 2014.

[9] K. Mařík, Z. Schindler, and P. Stluka, "Decision support tools for advanced energy management," Energy, vol. 33, no. 6, pp. 858-873, 2008.

[10] A. P. Prato, F. Strobino, M. Broccardo, and L. P. Giusino, "Integrated management of cogeneration plants and district heating networks," Appl. Energy, vol. 97, pp. 590-600, Sep. 2012.

[11] R. Hashemi, "A developed offline model for optimal operation of combined heating and cooling and power systems," IEEE Trans. Energy Convers., vol. 24, no. 1, pp. 222-229, Mar. 2009.

[12] H. Gadd and S. Werner, "Achieving low return temperatures from district heating substations," Appl. Energy, vol. 136, no. 0, pp. 59-67, Dec. 2014

[13] H. Lund, S. Werner, R. Wiltshire, S. Svendsen, J. E. Thorsen, F. Hvelplund, and B. V. Mathiesen, "4th generation district heating (4GDH)," Energy, vol. 68, pp. 1-11, Apr. 2014. 
[14] D. Buoro, P. Pinamonti, and M. Reini, "Optimization of a distributed cogeneration system with solar district heating," Appl. Energy, vol. 124, pp. 298-308, 2014.

[15] J. Dorfner and T. Hamacher, "Large-scale district heating network optimization," IEEE Trans. Smart Grid, pp. 1-8, 2014.

[16] Y. P. Cai, G. H. Huang, Q. G. Lin, X. H. Nie, and Q. Tan, "An optimization-model-based interactive decision support system for regional energy management systems planning under uncertainty," Expert Syst. Appl., vol. 36, no. 2, Part 2, pp. 3470 - 3482, 2009.

[17] M. Murai, Y. Sakamoto, and T. Shinozaki, "An optimizing control for district heating and cooling plant," in Proc. the 1999 IEEE International Conference on, 1999, vol. 1, pp. 600-604, vol. 1.

[18] A. M. Pantaleo, S. Giarola, A. Bauen, and N. Shah, "Integration of biomass into urban energy systems for heat and power. Part I: An MILP based spatial optimization methodology," Energy Convers. Manag., vol. 83, pp. 347-361, Jul. 2014.

[19] A. M. Pantaleo, S. Giarola, A. Bauen, and N. Shah, "Integration of biomass into urban energy systems for heat and power. Part II: Sensitivity assessment of main techno-economic factors," Energy Convers. Manag., vol. 83, pp. 362-376, Jul. 2014

[20] G. Chicco and P. Mancarella, "Assessment of the greenhouse gas emissions from cogeneration and trigeneration systems. Part I: Models and indicators," Energy, vol. 33, no. 3, pp. 410-417, Mar. 2008.

[21] P. Mancarella and G. Chicco, "Assessment of the greenhouse gas emissions from cogeneration and trigeneration systems. Part II: Analysis techniques and application cases," Energy, vol. 33, no. 3, pp. 418-430, Mar. 2008

[22] A. Arnette and C. W. Zobel, "An optimization model for regional renewable energy development," Renew. Sustain. Energy Rev., vol. 16, no. 7, pp. 4606-4615, Sep. 2012.

[23] R. B. Hiremath, B. Kumar, P. Balachandra, and N. H. Ravindranath, "Decentralized sustainable energy planning of Tumkur district, India," Environ. Prog. Sustain. Energy, vol. 30, no. 2, pp. 248-258, Jul. 2011

[24] S. Fazlollahi and F. Marechal, "Multi-objective, multi-period optimization of biomass conversion technologies using evolutionary algorithms and mixed integer linear programming (MILP)," Appl. Therm. Eng., vol. 50, no. 2, pp. 1504-1513, 2013.

[25] S. Fazlollahi, G. Becker, and F. Maréchal, "Multi-objectives, multi-period optimization of district energy systems: III. Distribution networks," Comput. Chem. Eng., 2014.

[26] C. Maifredi, L. Puzzi, and G. P. Beretta, "Optimal power production scheduling in a complex cogeneration system with heat storage," in Energy Conversion Engineering Conference and Exhibit, 2000. (IECEC) 35th Intersociety, 2000, vol. 2, pp. 1004-1012.

[27] R. Baños, F. Manzano-Agugliaro, F. G. Montoya, C. Gil, A. Alcayde, and J. Gómez, "Optimization methods applied to renewable and sustainable energy: A review," Renew. Sustain. Energy Rev., vol. 15, no. 4, pp. 1753-1766, May 2011.

[28] E. Ikonen, I. Selek, J. Kovacs, M. Neuvonen, Z. Szabo, J. Bene, and J. Peurasaari, "Short term optimization of district heating network supply temperatures," in Energy Conference (ENERGYCON), 2014 IEEE International, 2014, pp. 996-1003.

[29] M. Liu, Y. Shi, and F. Fang, "Combined cooling, heating and power systems: A survey,” Renew. Sustain. Energy Rev., vol. 35, pp. 1-22, Jul. 2014.

[30] Department of Energy and Climate Change, "CHP finance," Department of Energy and Climate Change, 2008.

[31] Biomass Energy Centre, Renweable Heat Incentive, vol. 2014. Biomass Energy Centre, 2011.

[32] Department of Environment, Greenhouse Gas Conversion Factor Repository, vol. 2014. 2014.

[33] Biomass Energy Centre, Estimated Carbon Dioxide Emissions for Freight Transport, vol. 2014, Crown, 2011.

[34] Bristish Standards, "Energy management system application program interface (EMS-API) - Part 301: Common information model (CIM) base (IEC 61970-301:2011)," British Standards Institution, Nov. 2011

[35] K. Deb, A. Pratap, S. Agarwal, and T. Meyarivan, "A fast and elitist multiobjective genetic algorithm: NSGA-II," IEEE Trans. On Evol. Comput. vol. 6, no. 2, pp. 182-197, 2002.

[36] I. Petri, H. Li, Y. Rezgui, Y. Chunfeng, B. Yuce, and B. Jayan, “A HPC based cloud model for real-time energy optimisation," Enterp. Inf. Syst. pp. 1-21, May 2014.

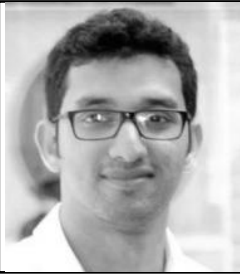

Bejay Jayan received the BEng degree in civil engineering and the Master's degree in sustainable energy and environment from Cardiff University, Cardiff, UK. $\mathrm{He}$ is currently pursuing the $\mathrm{PhD}$ degree in civil engineering at Cardiff University. During the first year of his $\mathrm{PhD}$, he has played an active role in two European FP7 projects SPORTE2 and RESILIENT, which are related to real time energy management in buildings (sport facilities) and districts respectively. Mr. Jayan is currently in his final year of research and is looking into utilizing knowledge bases/ontologies and intelligent techniques (such as neural networks, optimization) to support real time energy management at a building and district level.

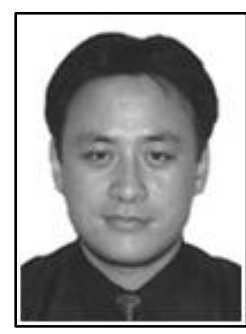

Haijiang Li since 1996, has been working large scale scientific computing research interfacingamong civil / structural engineering, architecture, life cycle constructionand facility management, large scale infrastructure modelling \& analysis,building energy, and water resource distribution and management. Hiskey expertise lies on the advanced and innovative computing basedlarge scale systems integration and decision making in support ofsustainable and resilient complex building/ infrastructure monitoring,modelling, analysis, optimization and management. It concerns how toleverage unlimited storage, high power computing, intelligent algorithmswith computerized domain knowledge to tackle key environmental challenges (e.g. energy and water). Dr. Li. is currently a senior lecturer of Engineering Informatics (BIM) \& Structural Applications at Cardiff University.

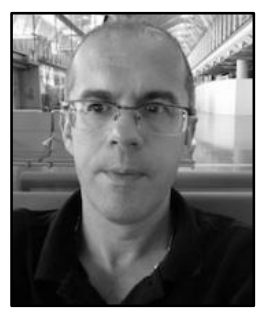

Yacine Rezgui received the MSc (diplmed etudesa pprofondies) degree in building sciences from the Universit Jussieu-Paris 6 and the PhD degree in computer science applied to the construction industry from ENPC (Ecole Nationale des Ponts et Chausses). He is a qualified architect and holds a BRE (building research establishment) chair in building systems and informatics at Cardiff University. Prof. Rezgui is also a member of the IEEE

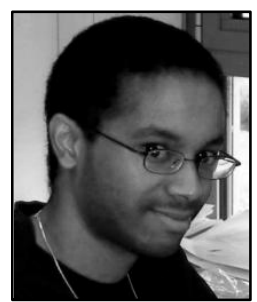

Jean-Laurent Hippolyte received the masters degree in parallel computingand multimedia systems in 2005 and the Ph.D. degree in computer science in 2009 from the University of Franche-Comte, Montbeliard, France. From 2009 to 2011, he was a research engineer in the energy conversion system design team in the FEMTO-ST Institute, Belfort, France. From 2011 to 2012, he worked as a post-doctoral researcher in the semantics team of VTT Technical Research Centre of Finland. Since 2012, Dr. Hippolytehas been a research associate in the BRE Centre for Sustainable Construction at Cardiff University, Cardiff, UK. His research interests include multi-objective optimization, energy system modeling, ontology engineering and knowledge management.

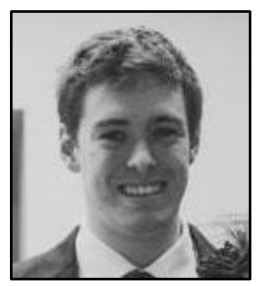

Shaun Howell received the BEng degree in civil engineering from Cardiff University, UK, in 2013. $\mathrm{He}$ is currently pursuing the $\mathrm{PhD}$ degree in civil engineering at Cardiff University, UK and continues to work on a number of EC FP7 projects. His research area is the application of ontologies towards the integrated development of SMART cities and their holistic optimization. Mr. Howell's awards and honors include the ICE prize for graduating top in his class, the Page prize for achieving the highest attainments during years 1 and 2 of the degree, the Cels a Steel prize for best steel and concrete structure project and the ground engineering prize for the largest contribution to the field within his class. 